\title{
THE STUDY OF MORPHOLOGY AND MORPHOMETRY OF ACETABU- LUM ON DRY BONES
}

\section{Gangavarapu Sreedevi ${ }^{* 1}$, Muralidhar Reddy Sangam ${ }^{2}$.}

\author{
${ }^{{ }_{1}}$ Assistant Professor, Department of Anatomy, NRI Medical College, Chinakakani, Guntur, Andhra \\ Pradesh, India. \\ 2 Professor \& HOD, Department of Anatomy, NRI Medical College, Chinakakani, Guntur, Andhra \\ Pradesh, India.
}

\section{ABSTRACT}

Background: Acetabulum is a deep cup shaped cavity present on the lateral aspect of the hip bone, which is contributed by three bones (i.e. - ilium, ischium \& pubis) bounded by a ridge known as rim of acetabulum. This aperture is divided into articular \& non-articular part, non-articular part is called as acetabular fossa covered by pad of fat $\&$ articular part is known as lunate surface articulating with head of femur forming the hip joint. The articular part of acetabular cavity is deficient inferiorly (acetabular notch) where it ends anteriorly as pointed and posteriorly as semilunar shaped.

Purpose of study: To obtain the morphometric data of acetabular cavity and to determine the relation between diameter and depth of acetabular cavity and to study the morphology of anterior acetabular ridge and ends of acetabular labrum.

Materials and Methods: Human adult dry hip bones 80 ( 39 right and 41 left) of unknown age and sex were collected from the Department of Anatomy, NRI Medical College, Chinakakani. Bones with osteoarthritis of hip, evidence of trauma or any other skeletal disorders were excluded. Three morphometrical and two morphological parameters were evaluated. Measurements of diameter, depth of acetabulam and width of acetabular notch were taken by digital vernier calipers and correlation between parameters were analysed using pearson correlation test.

Results: In the present study, the mean diameter of acetabulum on right and left sides is $49.40 \pm 3.5 \mathrm{~mm}$, $48.06 \pm 5.65 \mathrm{~mm}$ respectively and mean depth on right and left sides is $24.09 \pm 2.69 \mathrm{~mm}, 25.16 \pm 2.84 \mathrm{~mm}$. The width of acetabular notch on right and left sides were $22.25 \pm 2.97 \mathrm{~mm}, 22.52 \pm 2.46 \mathrm{~mm}$ respectively. Anterior acetabular ridge was curved in $43.75 \%(35)$, straight in $27.5 \%(22)$, angular in $22.5 \%(18)$, and irregular in $6.25 \%(5)$ of bones and $64(80 \%)$ hip bones showed pointed anterior end and lunate posterior end, in 12 bones (15\%) anterior and posterior ends of labrum are lunate shaped, in 4 bones (5\%) both anterior and posterior ends of labrum are pointed.

Conclusion: Knowledge of the dimensions of acetabulum are vital to understand the mechanics of hip joint, and will assist the prosthetists to construct the suitable prostheses and helps the surgeons in determining the dysplasia of acetabulum and in total hip arthroplasty

KEY WORDS: Acetabulum, Prostheses, Hip Arthroplasty.

Address for Correspondence: Dr Gangavarapu Sreedevi, Assistant Professor, Department of Anatomy, NRI Medical College, Chinakakani, Guntur-522503, Andhra Pradesh, India.

Mobile: 9849591825 E-Mail: gangavarapus13@gmail.com

\begin{tabular}{|c|c|c|}
\hline \multicolumn{3}{|c|}{ Access this Article online } \\
\hline \multirow{2}{*}{$\begin{array}{l}\text { Quick Response code } \\
\text { DoI: } 10.16965 / \text { ijar.2017.395 }\end{array}$} & \multicolumn{2}{|c|}{$\begin{array}{l}\text { Web site: International Journal of Anatomy and Research } \\
\qquad \text { ISSN 2321-4287 } \\
\text { www.ijmhr.org/ijar.htm }\end{array}$} \\
\hline & $\begin{array}{l}\text { Received: } 05 \text { Aug } 2017 \\
\text { Peer Review: } 07 \text { Aug } 2017 \\
\text { Revised: None }\end{array}$ & $\begin{array}{l}\text { Accepted: } 03 \text { Oct } 2017 \\
\text { Published (O): } 01 \text { Nov } 2017 \\
\text { Published (P): } 01 \text { Nov } 2017\end{array}$ \\
\hline
\end{tabular}




\section{INTRODUCTION}

Acetabulum is a deep cup shaped cavity present on the lateral aspect of the hip bone, which is contributed by three bones (i.e. - ilium, ischium \& pubis) bounded by a ridge known as rim of acetabulum [1]. This aperture is divided into articular \& non-articular part, non-articular part is called as acetabular fossa covered by pad of fat $\&$ articular part is known as lunate surface articulating with head of femur forming the hip joint. The articular part of acetabular cavity is deficient inferiorly (acetabular notch) where it ends anteriorly as pointed and posteriorly as semilunar shaped. Displacement of hip joint is one of the commonest congenital disorders in which the head of femur is not properly articulated inside the shallow acetabular cavity. In this situation patient has to undergo hip arthroscopy at the earliest [2]. The acetabular images aid the surgeon to determine the correct size of the acetabular cup during total hip arthroplasty and to realign the acetabulum back to normal position [3]. A bigger roof of the acetabular cup means a good grip of the head of the femur inside the acetabulum and hence a better result of arthroplasty[4]. An incongruous joint is more prone to develop degenerative changes than a joint having normal anatomy[5]. Knowledge of the dimensions of acetabulum are vital to understand the mechanics of hip joint, and will assist the prosthetists to construct the suitable prostheses and helps the surgeons in determining the dysplasia of acetabulum and in total hip arthroplasty $[6,7,8]$.

Morphology of anterior acetabular ridge is clinically important during total hip arthroplasty. Govsa etal[9] described the anterior acetabular ridge's shape morphologically. Posterior acetabular ridge almost always forms a simple semicircle. However the anterior acetabular ridge shows variations and because of these variations, the amount of anteversion is affected by the point of measurement along the anterior ridge [10].

Geometric discrepancies between the natural acetabulum and implant can result in painful lliopsoas impingement, attributable to prosthetic overlap at the anterior acetabular ridge over which the iliopsoas tendon extends to leave the pelvis [11].

Int J Anat Res 2017, 5(4.2):4558-62. ISSN 2321-4287
Han et. all[12] tried to determine the utility of several acetabular parameters in acetabular dysplasia diagnosis. Aktao et al[13] described the acetabular dysplasia frequency and normal hip joint morphometry in adult Turks.

The aim of the present study is to obtain the morphometric data of acetabular cavity and to determine the relation between diameter and depth of acetabular cavity and to study the morphology of anterior acetabular ridge and ends of acetabular labrum which has a role in diagnosing the congenital acetabular dysplasia and to provide data for preoperative assessment of acetabulum for total hip arthoplasty.

\section{MATERIALS AND METHODS}

Fig. 1: Measurement of diameter of acetabulum.

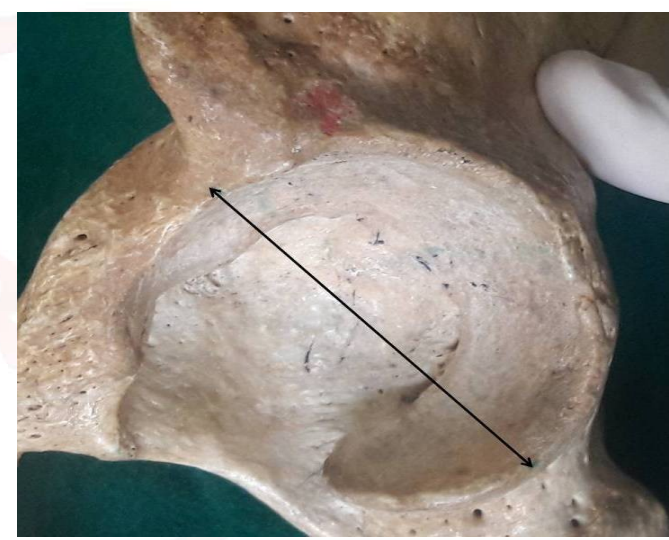

Fig. 2: Measurement of depth of acetabulum.

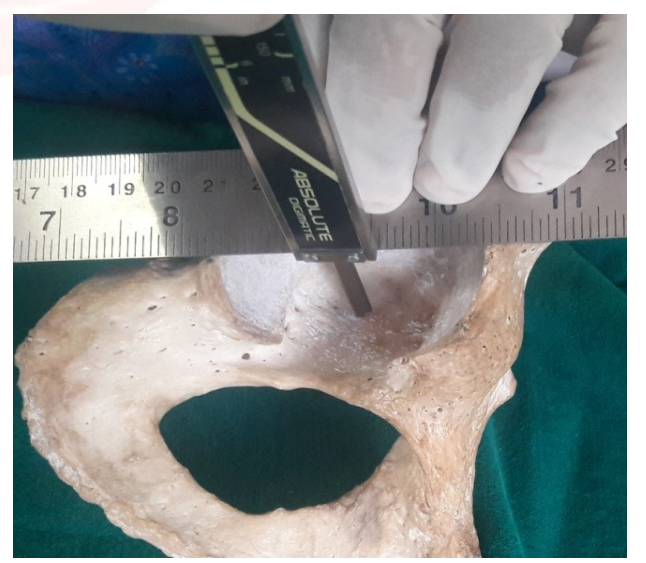

Fig. 3: Measurement of width of acetabular notch.

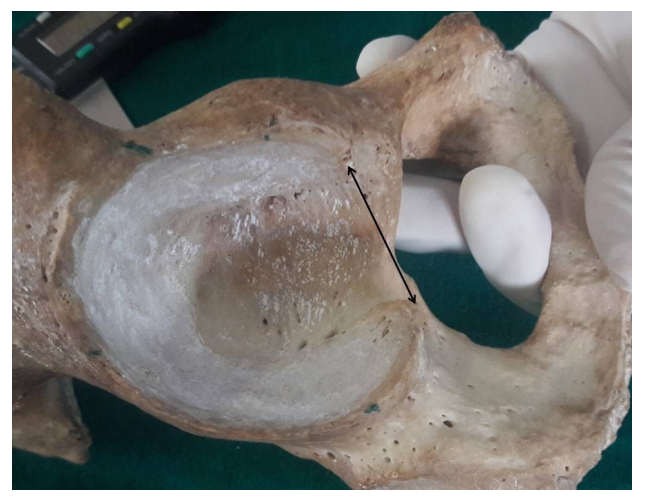


Human adult dry hip bones 80 ( 39 right and 41 left) of unknown age and sex were collected from the Department of Anatomy, NRI Medical College, Chinakakani. Bones with osteoarthritis of hip, evidence of trauma or any other skeletal disorders were excluded. Three morphometrical and two morphological parameters were evaluated. Measurements of diameter, depth of acetabulam and width of acetabular notch were taken by digital vernier calipers and correlation between parameters was analysed using pearson correlation test.

Diameter of the acetabulum: The distance between the acetabular ridge nearest to the ischial tuberosity to anterior iliac margin intersecting the acetabular ridge.(Fig1)

Depth of the acetabulum: A thin metallic scale was placed across the acetabulum. Depth of the acetabulum was measured in millimeters using digital sliding vernier calipers. Measurement could made as accurate as $1 / 10$ of a millimeter by this method (Fig2)

Width of acetabular notch: The distance between the two ends of lunate articular surface.(Fig3)

Anterior acetabular ridge shape was evaluated morphologically and classified as (curved, straight, angular\& irregular).

Ends of acetabular labrum: Shape of anterior end and posterior end of acetabulum was noted.

Table 1: Morphometric parameters of the acetabulum in the present study.

\begin{tabular}{|c|c|c|c|c|c|}
\hline Acetabulum & Side & Mean(SD)in mm & T value & Pvalue & significance \\
\hline \multirow{2}{*}{ Diameter } & Right & $49.40 \pm 3.52$ & \multirow{2}{*}{1.28} & \multirow{2}{*}{0.205} & \multirow{2}{*}{ No significance } \\
\hline & Left & $48.06 \pm 5.65$ & & & \\
\hline \multirow{2}{*}{ Depth } & Right & $24.09 \pm 2.69$ & \multirow{2}{*}{1.73} & \multirow{2}{*}{0.08} & \multirow{2}{*}{ No significance } \\
\hline & Left & $25.16 \pm 2.84$ & & & \\
\hline \multirow{2}{*}{$\begin{array}{c}\text { Width of acetabular } \\
\text { notch }\end{array}$} & Right & $22.25 \pm 2.97$ & \multirow{2}{*}{0.44} & \multirow{2}{*}{0.66} & \multirow{2}{*}{ No significanc } \\
\hline & Left & $22.52 \pm 2.46$ & & & \\
\hline
\end{tabular}

In the present study \pm correlation was observed between the diameter and depth of acetabular cavity as $r=0.2395, R^{2}=0.0574, p$ value- 0.03 showed significance.

There was no correlation between diameterof acetabular cavity and width of acetabular notch as $r=0.1055, R^{2}=0.01$, $p$ value- 0.35 - non significant

There is no correlation between width of acetabular notch and depth of acetabular cavity as $r=0.0544, R^{2}=0.003$, p value- 0.63 -not significant No significant difference is found between right and left side parameters. In the present study anterior acetabular ridge is curved in 35 (43.75\%), angular in $18(22.5 \%)$ straight in 22 $(27.5 \%)$ and irregular in $5(6.25 \%)$ bones. Fig 4

Fig. 4: Different types of anterior acetabular ridge/

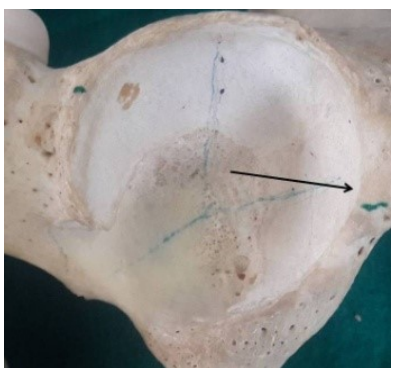

Curved

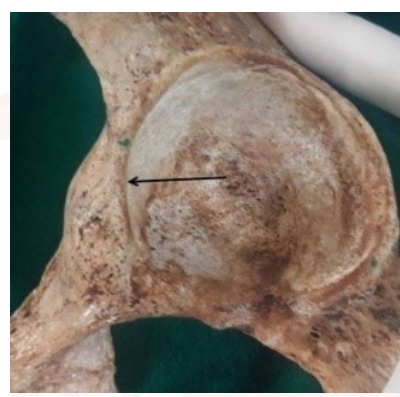

Straight

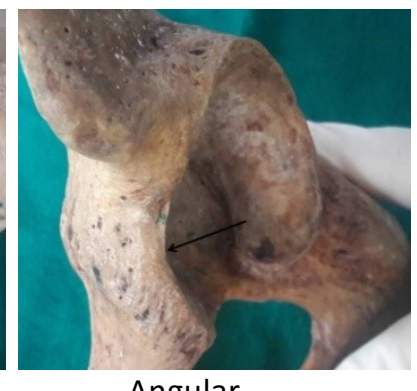

Angular

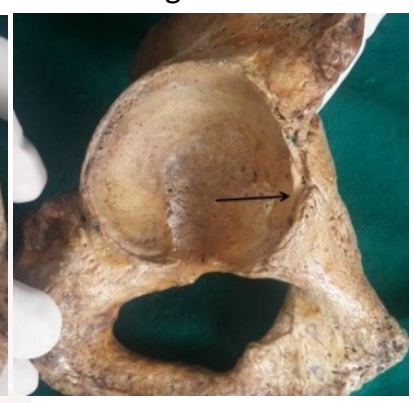

Irregular
In 64 (80\%) hip bones anterior end is pointed and posterior end is lunate , in 12 bones (15\%) anterior end and posterior ends of labrum are lunate and in 4 bones (5\%) both anterior and posterior ends of labrum are pointed (Fig 5).

Fig. 5: Different types of ends of acetabular labrum.
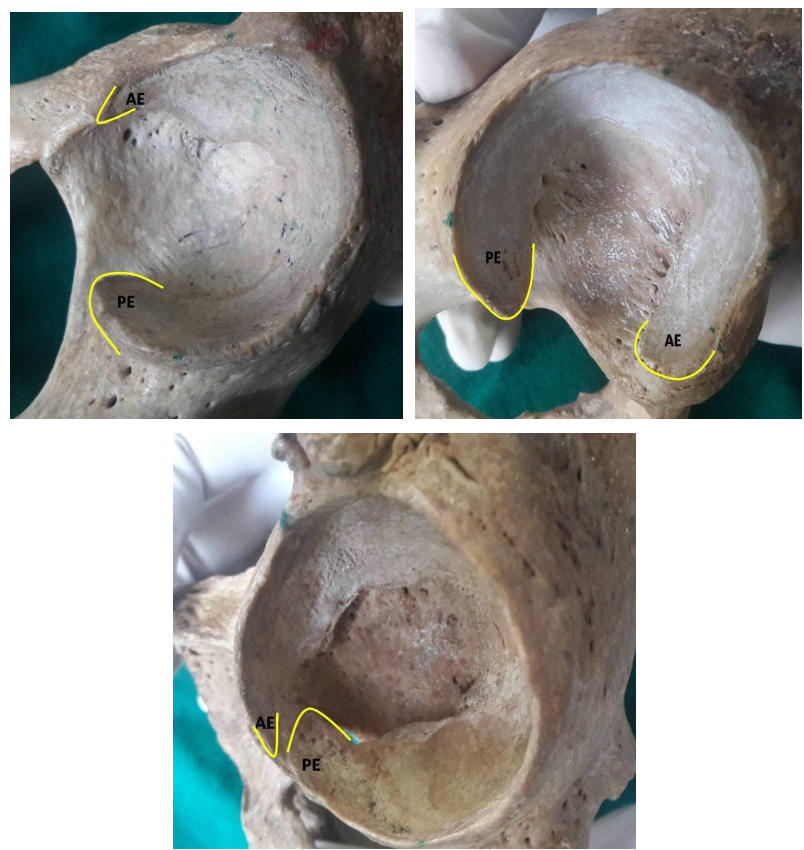

AE- pointed, PE- lunate AE \&PE- both pointed

( $A E$ - Anterior end, PE - Posterior end) 


\section{DISCUSSION}

In the present study, the mean diameter of acetabulum on right and left sides is $49.40 \pm 3.5 \mathrm{~mm}$, $48.06 \pm 5.65 \mathrm{~mm}$ respectively and mean depth on right and left sides is $24.09 \pm 2.69 \mathrm{~mm}, 25.16 \pm 2.84$ $\mathrm{mm}$. The observations in the present study were on par with those of previous studies.

Table 2: Showing the comparision of morphometric parameters of acetabular cavity with other studies.

\begin{tabular}{|c|c|c|c|}
\hline S.No. & Study & $\begin{array}{c}\text { Average diameter } \\
(\mathrm{mm})\end{array}$ & $\begin{array}{c}\text { Average depth } \\
(\mathrm{mm})\end{array}$ \\
\hline $\mathbf{1}$ & Funda et al[8] & $54.29 \pm 3.8$ & $29.49 \pm 4.2$ \\
\hline $\mathbf{2}$ & Gaurang et al[14] & $42.54 \pm 3.6$ & $19.07 \pm 2.47$ \\
\hline $\mathbf{3}$ & Bedita Devi [5] & $50.99 \pm 1.99$ & $28.32 \pm 1.32$ \\
\hline $\mathbf{2}$ & Yugesh et al[15] & Right: $47.4 \pm 0.23$ & Right: $29.9 \pm 0.21$ \\
\cline { 3 - 4 } & Left: $48.0 \pm 0.37$ & Left: $29.7 \pm 0.23$ \\
\hline \multirow{2}{*}{5} & Present study & Right: $49.40 \pm 3.5$ & Right: $24.09 \pm 2.69$ \\
\cline { 3 - 4 } & & Left: $48.06 \pm 5.65$ & Left: $25.16 \pm 2.84$ \\
\hline
\end{tabular}

Loder et al. [16] reported the acetabular depth has been regarded by many authors as an important measurement to define acetabular dysplasia. An acetabular depth of less than 0.9 $\mathrm{cm}$ is considered to be dysplastic. Sharp and Hull [17] reported that shallow acetabulum is more prone to develop congenital subluxation.

In the present study the width of acetabular notch on right and left sides were $22.25 \pm 2.97 \mathrm{~mm}$, $22.52 \pm 2.46 \mathrm{~mm}$ respectively where as they were $30.8 \pm 0.42 \mathrm{~mm}, 31.1 \pm 0.72 \mathrm{~mm}$ in a study by Yugesh et al [21].

In the present study anterior acetabular ridge was curved in $43.75 \%(35)$, straight in $27.5 \%(22)$, angular in $22.5 \%(18)$, and irregular in $6.25 \%(5)$ of bones.

Table 3: Showing the comparision of morphology of anterior acetabular ridge of various studies.

\begin{tabular}{|c|c|c|c|c|c|c|}
\hline $\begin{array}{c}\text { Shape of anterior } \\
\text { acetabular ridge }\end{array}$ & $\begin{array}{c}\text { Funda et al } \\
{[8](154)}\end{array}$ & $\begin{array}{c}\text { Maruyama } \\
\text { et al [10] }\end{array}$ & $\begin{array}{c}\text { Govas et al[9] } \\
(226)\end{array}$ & $\begin{array}{c}\text { Gaurang [14] } \\
(100)\end{array}$ & $\begin{array}{c}\text { Bedita Devi } \\
\text { et al [5] }\end{array}$ & $\begin{array}{c}\text { Present study } \\
(80)\end{array}$ \\
\hline Curved & $46.1 \%(71)$ & $60.5 \%(21)$ & $43.36 \%(98)$ & $61 \%(61)$ & $60 \%(60)$ & $43.75 \%(35)$ \\
\hline Straight & $23.3 \%(36)$ & $4.5 \%(9)$ & $11.94 \%(27)$ & $20 \%(20)$ & $4 \%(4)$ & $27.5 \%(22)$ \\
\hline Angular & $16.8 \%(26)$ & $25.50 \%(51)$ & $28.33 \%(64)$ & Not found & $27 \%(27)$ & $22.5 \%(18)$ \\
\hline Irregular & $13.6 \%(21)$ & $9.5 \%(19)$ & $16.37 \%((37)$ & $19 \%(19)$ & $9 \%(9)$ & $6.25 \%(5)$ \\
\hline
\end{tabular}

Maruyama etal [10] evaluated the morphology of anterior acetabular ridge to perform the hip joint implants correctly. The observations in the present study are correlating with Funda et al [8]. In the present study 64 (80\%) hip bones showed pointed anterior end and lunate posterior end, in 12 bones (15\%) anterior and posterior ends of labrum are lunate shaped, in 4 bones (5\%) both anterior and posterior ends of labrum are pointed. Yugesh et al [15] reported that in 93.3\% of the bones anterior end is pointed and the posterior end is lunate shaped, in $5 \%$ bones anterior and posterior ends are lunate in shape and in $1.7 \%$ bones the anterior and posterior ends are pointed.

\section{CONCLUSION}

A thorough knowledge of dimensions of acetabulum will assist the biomedical engineers to construct suitable prostheses. Various parameters of acetabulum observed in the present study can be used in total hip replacement to evaluate the acetabulum as a part of preoperative planning.

\section{ACKNOWLEDGEMENTS}

I am thankful to Mrs. Saritha who helped me in doing statistical analysis and Mrs. Rajyalakshmi , Mr.Jermia for their technical and non technical assistance.

\section{Conflicts of Interests: None}

\section{REFERENCES}

[1]. Standring S. Gray's Anatomy. Thirty-ninth Edition. Elsevier Churchill Livingstone 2005; 1421.

[2]. Umer M, Thambyah A, Tan WTJ, Das. Acetabular morphometry for determining hip dysplasia in Singapore population. J of Ortho Surgery. 2006; 14:27-30.

[3]. Hozack WJ, Parvizi J, and B Bender. Surgical treatment of hip arthritis, reconstruction, replacement and revision. 2010. 1st edition, Saunders Elsevier, Philadelphia.

[4]. Denham RA, Alexander LW. Arthroplasty of hip . J Bone Joint Surg 1957; 39B: 614-22.

[5]. Thoudam Bedita Devi, Chandra philip actabulaumMorphological and morphometrical study . Research Journal of Pharmaceutical, Biological and Chemical Sciences Nov- Dec 2014, 5(6) Page No. 799.

[6]. Chauhan R, Paul S, Dhaon BK. Anatomical Parameters of North Indian Hip joints- Cadaveric study . Journal of Anatomical Society of India. 2002; 51(1):39-42.

[7]. Mohd yusuf Baharuddin, Ahmad Hafiz Zulkifly, Mohmmed Rafiq, Abdul Kadir, Azlin saat, Azian Abdul et al. Morphometric study of acetabulum in Malay population Normal hips and its clinical applications. Journal of Medical sciences 2008; 466 (2): 417-423.

[8]. Funda Tastekin Aksu,Nazh Gulrizceri, Candan Arma, Suleyman Tetik- Morphology and morphometry of acetabulum, International Journal of Biological \& Medical Research, 2006, 143-148. 
[9]. Govsa F, Ozer MA, Ozgur Z. Morphologic features of the acetabulum. Arch Orthop Trauma Surg 2005; 125: 453- 461.

[10]. Maruyama M, Feinberg JR, Capello WN, D'antonio JA. Morphologic features of the acetabulum and femur: anteversion angle and implant positioning . Clin Orthop 2001;1:52 -65.

[11]. Eric vandenbussche, Mohammed saffarini, Fabienne Taillieu and Celine Mutscher. The asymmetric profile of acetabulum . Clin Orthop Relat Res 2008; 466 (2): 417-423.

[12]. Han CD, Yoo JH, Lee WS, Choe WS. Radiographic parameters of acetabulum for dysplasia in Korean adults Yonsei Med J 1998; 39: 404-408.

[13]. Aktas S, Pekindil G, Ercan S, Pekindil Y. Acetabular dysplasia in normal Turkish adults. Bull Hosp Jt Dis 2000; 59: 158-162.

[14]. Gaurang paramara, Srushti Rupra reliab, SV Patel C, SM Patel B, Dr Nishita Jethvaa. Morphology and morphometry of acetabulumint J Biol Med Res 2013;4(1):2924-2926.
[15]. Yugesh and Senthil Kumar S. Morphometric analysis of acetabulum and its clinical correlation in south Indian population. IJAR 2016; 2(6): 10111014.

[16]. Loder RT, Mehbod AA, Meyer C, Meisterling M. Acetabular depth and race in young adults; A potential explanation of the differences in the prevalence of slipped capital femoral epiphysis between different racial groups. J Pediatric Orthop. 2003; 23:699-702.

[17]. Sharp IK, Hull. Acetabular Dyspalsia and the Acetabular angle. Journal of Bone and Joint Surgery. 1961; 43(2):268- 272.

How to cite this article:

Gangavarapu Sreedevi, Muralidhar Reddy Sangam. THE STUDY OF MORPHOLOGY AND MORPHOMETRY OF ACETABULUM ON DRY BONES. Int J Anat Res 2017;5(4.2):4558-4562. DOI: 10.16965/ ijar.2017.395 